\title{
Rondônia: A luta dos indígenas por suas terras e sua identidade
}

\author{
Rondônia: The indigenous struggle \\ for their lands and their identity
}

José Monserrat Filho ${ }^{1}$

Recebido em abril de 2018

Aceito em maio de 2018

\begin{abstract}
Resumo:
Rondônia tem 1,800 milhão de habitantes vivendo em 243 mil km² (2,87\% do território nacional). Entre eles, estão - ou deveriam estar -60 povos indígenas, que ainda congregam algo em torno de 15 mil sobreviventes. Conheci três desses povos resistentes e li o que pude sobre outros. Foi minha primeira viagem à região, da qual acabo de voltar. Volto atormentado, confuso e confiante diante de uma realidade brutal, onde, apesar de tudo, a esperança ainda teima em soprar. Este artigo trata da realidade vivenciada.
\end{abstract}

Palavras-chave: Rondônia. Povos Indígenas. História. Terras Indígenas. Demarcação.

\begin{abstract}
:
Rondônia has 1,800 million inhabitants living in 243 thousand $\mathrm{km}^{2}$ (2.87\% of the national territory). Among them are - or should be - 60 indigenous peoples, who still congregate something around 15 thousand survivors. I met three of these resistant people and read what I could about others. It was my first trip to the region, from which I have just returned. I come back tormented, confused and confident in the face of a brutal reality, where, despite everything, hope still persists in blowing. This article deals with the reality experienced.
\end{abstract}

Keywords: Abstract: Rondônia. Indigenous people. History. Indigenous Lands. Demarcation.

\footnotetext{
${ }^{1}$ José Monserrat Filho, Vice-Presidente da Associação Brasileira de Direito Aeronáutico e Espacial (SBDA), ex-Chefe da Assessoria de Cooperação Internacional do Ministério da Ciência e Tecnologia (2007-2011) e da Agência Espacial Brasileira (AEB) (2011-2015), Diretor Honorário do Instituto Internacional de Direito Espacial, e Membro Pleno da Academia Internacional de Astronáutica. Ex-diretor da revista Ciência Hoje e editor do Jornal da Ciência, da SBPC, autor de Politica e Direito na Era Espacial - Podemos ser mais justos no Espaço do que na Terra?, Ed. Vieira\&Lent, 2017. E-mail: <jose.monserrat. filho@gmail.com>.
} 
E existe um povo que a bandeira empresta Para cobrir tanta infâmia e covardia! Castro Alves (1847-1871), o poeta dos escravos, o canto dos aflitos.

Rondônia tem 1,800 milhão de habitantes vivendo em 243 mil km² ( $2,87 \%$ do território nacional). Entre eles, estão - ou deveriam estar - 60 povos indígenas, que ainda congregam algo em torno de 15 mil sobreviventes. Conheci três desses povos resistentes e li o que pude sobre outros. Foi minha primeira viagem à região, da qual acabo de voltar. Volto atormentado, confuso e confiante diante de uma realidade brutal, onde, apesar de tudo, a esperança ainda teima em soprar.

Foram 12 dias que jamais esquecerei. Não pelo gado incontável pastando bovinamente em fazendas imensas e exuberantes. Nem pelos majestosos campos de soja. Nem ainda pela devastação de árvores milenares e o roubo descarado da farta e milionária madeira, que abrem caminho às vacas e bois e à soja para o enriquecimento de uma minoria poderosa, com pleno apoio das mais altas autoridades dos governos locais e federais. Mas pela descoberta de como funcionam a crueldade sabiamente escondida e o genocídio permanente e silencioso, que permitem e incentivam essa barbárie toda.

Tive o privilégio de participar da missão do Conselho Indigenista Missionário (CIMI), integrada pela Irmã Emília Altini, o Frei Volmir Bavaresco e a professora Ruth Monserrat, linguista, especializada em línguas indígenas brasileiras, e minha esposa há séculos. Missão para ajudar os povos indígenas a salvarem o que resta de suas línguas, que continuam a ser dizimadas junto com seus antigos falantes e os que ainda se empenham heroicamente em mantê-las.

Recebido pelo Papa Francisco, no Vaticano, em 29 de junho de 2016, o presidente do CIMI e arcebispo de Porto Velho, dom Roque Paloschi, entregou ao pontífice o Relatório da Violência contra os Povos Indígenas de 2014 e uma carta em que agradece a atenção por ele dedicada à questão indígena, falando das dificuldades enfrentadas pelos povos indígenas, não só em Rondônia, mas em quase todo o Brasil.

"A história dos povos indígenas é deturpada - na maioria das vezes - nas escolas e até nas universidades. A falta de conhecimento adequado da verdadeira história dos primeiros habitantes da Amazônia e do Brasil é uma das causas dos preconceitos e da discriminação de que os povos indígenas até hoje são vítimas", afirmou o ex-presidente do CIMI, dom Erwin Kräutler - nascido na Áustria e hoje bispo do Xingu - no texto de abertura do Panewa Especial de 2015, com 160 páginas. Esse livro, meu guia, ajuda a conhecer a real trajetória dos povos indígenas do Brasil e a descobrir seu inestimável valor, a riqueza de suas culturas e sua preciosa contribuição à espécie humana.

Os povos indígenas que há milênios habitavam a América Latina foram desprezados e acusados de "selvagens, ferozes e traiçoeiros". O próprio nome 
que logo lhes foi dado equipara-os aos bichos do mato, conta dom Erwin Kräutler. E acrescenta: As Constituições do Brasil anteriores a 1988 falavam em "terra dos silvícolas" e da "incorporação dos silvícolas à comunhão nacional". Isso condenava os indígenas à perda de sua identidade. Pertencer à "comunidade nacional" era, na realidade, deixar de ser indígena e abrir mão de suas terras tradicionais, "chão de seus ritos e mitos e lugar sagrado onde estavam sepultados seus antepassados". Muito da vastidão dos latifúndios nacionais e hoje também estrangeiros - digo eu - nasceu e cresceu por ali.

Rondônia tinha cerca de 80 mil indígenas, quando os bravos "conquistadores" ali chegaram, recorda ainda dom Erwin Kräutler. Hoje tem menos de 15 mil, ou seja, apenas 18\% do que tinha há 500 anos. Em 500 anos, portanto, Rondônia perdeu mais de $80 \%$ de seus povos nativos. Por que morreram/mataram tantos indígenas? Pergunte aos "conquistadores" de ontem e de hoje. A razão, no fundo, é sempre a mesma: índio bom é índio morto. Deixa a terra livre, nada reivindica, não aporrinha, não enche o saco. Inacreditável: o povo Puruborá, hoje com 220 integrantes, teve que comprar um pedaço de suas próprias terras para poder sobreviver... Até quando?

"A sociedade que chamamos de civilizada ainda não vê o indígena como irmão, como pessoa humana de igual natureza e direitos. A sociedade dos shopping centers e dos supermercados está longe de compreender a possibilidade de pessoas viverem em plena comunhão com a natureza mantendo sua própria identidade", critica dom Bruno Pedron, bispo de Ji-Paraná e prócer do CIMI de Rondônia. Muitos homens de negócios, nem sempre claros, se proclamam defensores intransigentes da Natureza, mas nela não incluem os povos que vivem entrosados até a alma com ela e a conhecem na palma da mão. A natureza, para esses ecólogos de balcão, não passa de magnífica fonte de renda.

A propósito, "os poderes econômicos continuam a justificar o sistema mundial atual, onde predominam uma especulação e uma busca de receitas financeiras que tendem a ignorar todo o contexto e os efeitos sobre a dignidade humana e sobre o meio ambiente. Assim se manifestam - intimamente ligadas - a degradação ambiental e a degradação humana e ética", acentua o Papa Francisco em sua Encíclica Laudato Si' (Louvado Sejas) sobre o cuidado da casa comum (Edições Paulinas, 2015, p. 46). E arremata: "Qualquer realidade que seja frágil, como o meio ambiente, fica indefesa perante os interesses do mercado divinizado, transformados em regra absoluta".

Não por acaso, cerca de $90 \%$ das terras indígenas de Rondônia estão, neste momento, invadidas. É uma invasão sem retorno, irreversível, invasores e proprietários usurpadores não têm dúvidas a respeito. Ao contrário dos indígenas, eles não têm motivo algum para temer o amanhã, nem o depois de amanhã. Toda a estrutura oficial, o cordão dos puxa-sacos chapa branca, muito bem pago, joga a favor deles o tempo todo. E ai de quem abra o bico para 
falar mal da "irrepreensível legalidade" dos donos da justiça! Poderá sumir sem deixar vestígios. E terá muita sorte se seu corpo for encontrado.

Os povos Kujubim, Puruborá e Arara, nesta ordem, foram os que conheci mais de perto nesse recorrido por Rondônia. Pelo Censo de 2014, o povo Kujubim, expulso de suas terras tradicionais, tem hoje apenas em torno de 131 membros. E só em 2007 foi reconhecido pela FUNAI (Fundação Nacional do Índio), órgão oficial criado em 1967 para substituir o Serviço de Proteção aos Índios (SPI), fundado em 1910, que teve políticas contraditórias, ora beneficiando, ora contribuindo para a destruição física e cultural dos indígenas. No século XVIII, quando espanhóis e portugueses lutavam pela posse de terras na fronteira ainda não claramente demarcada, os Kujubim e outros povos foram escravizados como mãos de obra para a construção do Forte Príncipe da Beira. Mais tarde, os seringueiros invadiram as terras dos Kujubim em busca do ouro branco, o látex, submetendo-os ao trabalho semiescravo no corte dos seringais e abandonando-os ao serem dizimados pelo sarampo, espalhado criminosamente. Mas em 2013, na cidade de Costa Marques, nascia a Associação Indígena do Povo Kujubim, para fortalecer a organização do povo e a luta pela retomada de seu território secular. A luta continua.

Os Puruborá, por sua vez, são um povo sem terra, embora seu território tradicional tenha sido demarcado por ninguém menos que o Marechal Rondon, que os contatou em 1919. Até 2000, a FUNAI considerava extintos os Puruborá. Eles teriam sido dizimados por epidemias de gripe, sarampo, catapora e caxumba, provavelmente encomendadas. Hoje, há cerca de 220 sobreviventes. Em 2001, eles reivindicaram terras de forma oficial, em carta ao Ministério Público e à FUNAI. Em 2017, 16 anos mais tarde, o pedido legal deve estar propositalmente perdido em alguma gaveta burocrática. Os Puruborá tinham língua própria, oriunda do tronco Tupí. Hoje, catam palavras e frases enterradas no tempo junto de seus ancestrais. E os jovens recuperam seus mitos e pinturas. Emília Puruborá era a memória viva do povo, exemplo da força de suas mulheres. Ela e o marido tiveram de comprar a terra onde viviam, parte do território histórico do povo. A filha de Emília, Cacique Hosana, ativa e decidida como a mãe, é hoje a líder Puruborá. Em 2014, uma assembleia do povo criou a Associação Indígena Puruborá Maxajá. Mas a luta por suas terras não cessa, mesmo diante das ameaças e de dificuldades aparentemente insuperáveis.

O povo Arara tem hoje 378 pessoas (Censo de 2014). Elas falam sua própria língua e vivem em área de 185.534 ha, no Igarapé Lourdes, município de JiParaná, junto com seu antigo rival, o povo Gavião, expulso de seu território tradicional por fazendeiros. Graças à resistência do povo Arara, a área foi demarcada, homologada por decreto e registrada em 1976. Mas atenção: 185.534 hectares equivalem a $1.885 \mathrm{~km}^{2}$. Isso é muito pouco comparado com o que os Arara tinham antes. Não é atoa que boa porção de seu território tradicional é parte hoje do município de Ji-Paraná. Um de seus clamores mais conhecidos 
diz: "Nós somos gente! Temos nossa história e nossa cultura para preservar e contar." E mais: "Como escravos fomos tratados, nossos pais foram enganados e explorados, de nossas famílias fomos tirados e trocados como mercadorias. Mesmo longe, ficava pensando: onde estão meus parentes?"

A fala lúcida do Cacique Pedro emociona até quem não é índio: "Sabemos que não vivemos como vivíamos antes, não esquecemos nada do que vivemos naquele tempo, mas hoje a nossa luta é muito grande, temos que lutar para não perder nossa identidade, mas também temos a luta constante para nos mantermos vivos em cima do que restou de nossas terras. Muitas de nossas festas e rituais, não realizamos mais, não porque não queremos, mas porque não temos o lugar adequado, muitos de nossos lugares sagrados se perderam, hoje são pastos, fazendas, estradas e cidades. Tudo para nós ficou limitado, quantas comidas e frutas que existiam e hoje não existem mais. Mas o fato de estarmos em cima de nossa terra é prova de que estamos vivos, que nós existimos e vamos seguir lutando até o último índio vivo.”

Demarcação e respeito já, para não termos nunca um "último índio vivo". 